This is the penultimate draft. Please cite published version: The Journal of Aesthetics and Art Criticism, March 2018, Vol.76(2), pp.201-212.

\title{
Sugar and spice, and everything nice: What rough heroines tell us about imaginative resistance
}

\begin{abstract}
This paper examines the asymmetry between our engagement with male characters in fictional narratives who transgress moral norms and female characters who do the same. I claim that rough heroines present a new puzzling instance of resistance phenomena that cannot be accounted for by even the most recent accounts of imaginative resistance that incorporate considerations of narrative context, such as genre and narrative artistry. I sketch a solution that points to the violation of gender norms and the challenge to power dynamics as the source of resistance. I argue that rough heroines reveal an important element of narrative engagement that has been largely overlooked in the literature: appreciators' interpretive horizons.
\end{abstract}

\section{Introduction}

Gone Girl's Amy Dunne could have been the perfect rough heroine. Gillian Flynn writes her as a funny, smart and focused woman who decides to frame her husband for her own murder. In her Cool Girl monologue, she denounces how women's lives are defined by the male gaze, how they have to shape their identities to fit men's interests:

Men always say that as the defining compliment, don't they? She's a cool girl. Being the Cool Girl means I am a hot, brilliant, funny woman who adores football, poker, dirty jokes, and burping, who plays videogames, drinks cheap beer, loves threesomes and anal sex, and jams hot dogs and hamburgers into her mouth like she's hosting the world's biggest culinary gang bang while somehow maintaining a size 2, because Cool Girls are above all hot. Hot and understanding. Cool girls never get angry; they only smile in a chagrined, loving manner and let their men do whatever they want. Go ahead, shit on me, I don't mind, I'm the Cool Girl. (...) And the Cool Girls are even more pathetic: They're not even pretending to be the woman they 
want to be, they're pretending to be the woman a man wants them to be. Oh, and if you're not a Cool Girl, I beg you not to believe that your man doesn't want the Cool Girl. It might be a slightly different version - maybe he's a vegetarian, so Cool Girl loves seitan and is great with dogs; or maybe he's a hipster artist, so Cool Girl is a tattooed, bespectacled nerd who loves comics. There are variations to the window dressing, but believe me, he wants Cool Girl, who is basically the girl who likes every fucking thing he likes and doesn't ever complain.

Amy seeks to justify her misdeeds and secure appreciators' allegiance by explaining that she is enacting revenge because she grew tired of living up to men's expectations. It seems that this could have presented the perfect motivation for audiences to sympathise with an immoral character. And yet, David Fincher's film adaptation failed to make of Amy a compelling and engaging morally flawed protagonist. While the character from the book remained the same, the attitudes toward Amy prescribed to the audience changed: in failing to present and engage with her motivations in a meaningful way, the film positioned her as an antagonist. ${ }^{1}$ Amy Dunne became a villain so hated that audiences longed to see defeated. The same thing can be said of Game of Thrones' Cersei Lannister. The same, however, cannot be said of Walter White. Or Tony Soprano. Or Patrick Bateman.

There seems to be an asymmetry between our engagement with male characters in fiction who transgress moral norms and female characters who do the same. This asymmetry can be found not only at the level of appreciators' responses but also at the level of artistic production: while the rough hero has thrived in recent years, the same cannot be said for rough heroines. The question is why. A. W. Eaton (2012) has argued that rough heroes represent a special kind of aesthetic achievement because audiences surmount their initial imaginative resistance to engage with these deeply flawed characters. But it would seem that audiences do not easily overcome imaginative resistance to rough heroines. This paper argues that rough heroines thus present a new puzzling instance of resistance phenomena.

We can formulate the puzzle of rough heroines as follows. Rough protagonists are deeply morally flawed characters that demand appreciators' allegiance; however, we can identify an asymmetry between our engagement with male and female characters who transgress moral norms: we seem to ally with rough heroes relatively easily, but we resist allying with rough heroines. Resisting rough heroines doesn't entail that either there aren't or there can't be 
instances of morally flawed female characters that secure appreciators' allegiance. As it has often been noted in the literature, resistance refers to a comparative difficulty, not an absolute imaginative failure. The phenomenon I want to highlight refers to: (a) the few instances of rough heroines in narrative works, compared to the high numbers of rough heroes; (b) the greater effort needed to generate strong and sustained pro-attitudes toward female protagonists who transgress moral norms; and (c) the common failure of uptake from audiences: although the narrative might present a woman as a rough heroine, audiences often regard her as an antagonist.

The phenomenon of resistance to rough heroines raises questions relating both to the creation and appreciation of works. But while these might be different questions, this paper addresses the issue by focusing on the difficulties in imaginatively engaging with rough heroines. That is, what I propose is that difficulties in imaginative engagement result not only in failure of uptake, but in reduced numbers of works featuring rough heroines. And I propose this is likely because the greater effort needed to imaginatively engage with rough heroines implies unique creative challenges, for example in the construction of characters.

Focusing on imaginative engagement, I will examine the puzzle of rough heroines as an instance of resistance phenomena. Although more recent proposals incorporate considerations of narrative context to explain variations in our imaginative engagement with morally deviant scenarios in fiction, I will argue that these cannot account for resistance to rough heroines. Because of this, I will argue that rough heroines tell us something about resistance phenomena and how narrative engagement is constrained.

In the first section, I will go over Eaton's characterization of rough heroes and the role immorality plays in appreciators' engagement with fictional narratives that feature these deeply morally flawed protagonists. The second section will briefly examine the puzzles of imaginative resistance to characterise the sort of resistance that is at play when appreciators engage with rough heroes. The aim of this section is to analyse why audiences overcome their initial resistance to rough heroes; I will note that only those accounts that incorporate considerations of narrative context, such as genre and narrative artistry, can properly accommodate appreciators' allegiance to deeply morally flawed protagonists. However, in the third section I will claim that the asymmetry found in our engagement with rough heroes and heroines challenges even those accounts that incorporate considerations of narrative context as an explanation to variability within resistance phenomena. In the final section, I will sketch a 
solution to the puzzle of rough heroines. This paper does not intend to provide a detailed account of appreciators' resistance to rough heroines, but rather to point to where the problem might be. What I will show by the end of the paper is that the puzzle of rough heroines reveals a different element of narrative engagement that has been neglected in the literature on imaginative resistance: appreciators' interpretive horizons.

\section{Rough heroes}

Most fictional narratives include morally flawed characters. But rough heroes are not simply morally flawed characters, they are morally flawed protagonists that demand appreciators' allegiance. The moral flaws of a rough hero are both central for the narrative and a core part of his personality. A. W. Eaton identifies five features of the rough hero: (1) his flaws are grievous, (2) his flaws are an integral part of his personality, (3) he fully intends to be bad and is remorseless, (4) the audience is not prescribed to forgive him or dismiss his actions as the result of misfortune, weakness or ignorance, and (5) his vices are not outweighed by other more redeeming features (Eaton 2012). Examples of rough heroes include American Psycho's Patrick Bateman or Alex in A Clockwork Orange.

Still, we might think that (3) and (5) are problematic. It might be difficult to find examples of rough heroes that simply aim to be bad; one might argue that even if they intentionally make immoral life choices and display immoral attitudes, they rarely explicitly aim at being immoral. It might also be difficult to find examples of rough heroes that do not display any kind of remorse, even if momentary. More importantly, it seems that if rough heroes indeed lacked any redeeming features, appreciators would be unlikely to display the relevant pro-attitudes. So it is worth making a few refinements to further characterise rough heroes. Rough heroes intentionally and knowingly engage in immoral actions; they rarely express remorse, and when they do, this remorse is not a central part of the narrative. Further, while rough heroes possess other redeeming features that ground appreciators' pro-attitudes, such as wit, intelligence, attractiveness or strength, these features should normally be regarded as morally irrelevant given the gravity of their misdeeds. We could reformulate (3) and (5) as follows: $\left(3^{*}\right)$ the rough hero intentionally engages in immoral actions and his remorse is not a central part of the narrative; and $\left(5^{*}\right)$ his vices are not outweighed by other morally relevant features.

It is relevant to distinguish rough heroes from antiheroes. Antiheroes are protagonists that lack traditional heroic qualities and that are morally flawed in some respects, but whose flaws are 
outweighed by other moral virtues: antiheroes might be rough around the edges, but they ultimately possess other morally relevant redeeming features (Carroll 2008; Eaton 2010; Eaton 2012). Examples of antiheroes include Han Solo in Star Wars or Jimmy McNulty in HBO's The Wire. Nevertheless, it is worth noting that rough heroes and antiheroes do not seem to be two distinct and clear-cut categories. Rather, they seem to be two sides of a broader category of morally flawed protagonists. The difference between rough heroes and antiheroes is a matter of degree: the degree of severity of their moral flaws and misdeeds, the degree of remorse they display, and the degree of moral relevance of their redeeming features. Understanding rough heroes and antiheroes as part of a continuum of morally flawed characters allows us to make sense of problematic instances that do not seem to easily fit in either category, like Dexter Morgan in Dexter.

As I said, the moral flaws of rough heroes are not only a central part of their personality, but a central part of the narrative. Unlike villains, rough heroes are endorsed by the narrative's perspective. Noël Carroll has argued against Eaton's account of rough heroes that we must not mistake a character's immorality with an endorsement of that immorality by the narrative. According to Carroll, rough heroes cannot be said to be endorsed by the narrative's perspective since the narrative clearly portrays them as evil (Carroll 2013, 372). However, Carroll fails to see what Eaton identifies as the rough hero's defining feature within a narrative: while he is indeed presented as immoral, audiences are prescribed strong pro-attitudes toward him that are sustained throughout the engagement with the narrative. I believe it's important to say that a narrative endorses rough heroes by prescribing these pro-attitudes.

Appreciators are meant to recognise at all times the defining immoral character of the hero, while at the same time displaying strong pro-attitudes toward him. More importantly, these pro-attitudes should be understood as something stronger than mere sympathy. Carl Plantinga defines sympathy as the concern for a character that is rooted in an emotional response, but that needn't be sustained throughout the entire narrative; thus, sympathies can be short term, shallow, and could be displayed towards characters that are not endorsed by the narrative's perspective, such as villains (Plantinga 2010). But appreciators are not only meant to sympathise with the rough hero: appreciators are prescribed to ally with rough heroes. Contrary to sympathy, allegiance must be defined as a strong pro-attitude that is extended throughout the engagement with a narrative (Plantinga 2010). Allegiance refers to the sustained, strong pro-attitudes that keep us invested in the success of a deeply morally flawed protagonist. $^{2}$ Characterising our pro-attitudes toward rough heroes as allegiance rather than mere sympathy 
allows us to make room for the fact that during our engagement with these narratives, we sometimes don't sympathise with the rough hero: sometimes we despise the rough hero and sympathise with his victims; and yet, we remain invested in seeing him prevail. While sympathy is rooted in an emotional response, allegiance is generally rooted on moral judgement. Rough heroes, however, require a special kind of allegiance that acknowledges the hero's depravity, but that guarantees our continued investment in his success. ${ }^{3}$ The next section will examine allegiance to rough heroes in the face of their moral failings.

Precisely because we condemn the rough hero but remain invested in his success, Eaton says that appreciators' engagement is characterised by conflicting attitudes that create tension (Eaton 2012, 285). The tension works like this. The narrative emphasizes the immoral character of the hero while at the same time endorsing him. That is, the narrative prescribes appreciators to ally with the rough hero by prescribing strong pro-attitudes that are extended throughout their narrative engagement. The endorsement of the rough hero generates resistance: appreciators initially refuse allegiance on the grounds of the hero's moral flaws. But, at the same time, the narrative generates such strong pro-attitudes toward the rough hero that appreciators overcome the original resistance, and ally with the morally flawed protagonist. For Eaton, this tension is the narrative's greatest artistic achievement. It takes "considerable artistry and finesse" for audiences to surmount resistance and fall for rough heroes. Even more so, these narratives are compelling because appreciators are "pulled in opposing directions without hope of relief and left to linger in a delicious state of irresolvable conflict with ourselves." (Eaton 2012, 287)

If the engagement with rough heroes depends on overcoming resistance because their immoral character is central to the narrative, it seems like the problem with rough heroines is that audiences cannot surmount resistance to ally with a morally flawed female protagonist. So what kind of resistance is at play, and why do audiences surmount it when it comes to rough heroes but not rough heroines?

\section{Falling for rough heroes}

In general, imaginative resistance refers to the difficulties appreciators seem to encounter during their engagement with fictional scenarios that involve certain forms of deviance. Although Tamar Szabó Gendler (2000) originally characterised it as a single puzzle regarding the comparative difficulty in imagining morally deviant propositions, ${ }^{4}$ Brian Weatherson 
(2004) and Kendall Walton (2006) have since identified at least four different resistancerelated ${ }^{5}$ puzzles: (1) the imaginative puzzle refers to the difficulties in imagining certain deviant propositions, (2) the fictionality or alethic puzzle refers to the difficulties in accepting as true in the fiction certain deviant propositions, (3) the phenomenological puzzle refers to why certain deviant propositions strike appreciators as confusing, and (4) the aesthetic puzzle refers to why certain deviant propositions impact a narrative's aesthetic value.

In addition to these four puzzles, however, I think it is necessary to identify a fifth resistancerelated phenomenon concerning the prescribed responses to the narrated events, and how these responses relate to our actual attitudes. In some cases, we encounter difficulties during our narrative engagement not merely because we are asked to imagine deviant propositions, but because we are asked to respond in ways we consider ethically inappropriate. In this sense, I propose to posit (5) the affective puzzle, which refers to why certain fictional scenarios that involve deviance trigger difficulties in adopting the affective attitudes prescribed. ${ }^{6}$ It is this affective puzzle that is relevant for understanding resistance to rough protagonists in narratives that clearly present them as immoral. Appreciators are not asked to imagine a deviant moral claim as true in the fictional world. But rather, appreciators are asked to respond with ethically inappropriate responses to the immoral character of the protagonist by displaying strong proattitudes that are sustained even in the character's darkest hour. The resistance triggered by rough protagonists is a resistance to enter into attitudes that fail to condemn an immoral character.

The affective resistance phenomenon is identified by Ronald De Sousa (2010), who claims that imaginative resistance can be explained by appreciators resisting to experience certain emotional responses, and by Peter Goldie (2003), who claims that in some cases we fail to fully engage with a fictional narrative because we do not allow ourselves to be emotionally carried along. This fifth resistance-related phenomenon was already present in Hume's discussion of the supposed asymmetry found in our engagement with speculative and evaluative deviance. While noting that appreciators do not seem to find speculative errors in literary works problematic, Hume claims that they do need to make a "very violent effort" to engage with moral deviance. In particular, Hume refers to the works' ability to arouse "sentiments of approbation or blame, love or hatred, different from those to which the mind from long custom has been familiarized" (Hume 1985, 247). What is important to note, therefore, is that Hume seems to be referring to an affective resistance in appreciators to enter into what they regard as deviant sentiments. That is, what seems puzzling about these cases is that appreciators 
encounter difficulties when they are asked not only to entertain deviant propositions, but to summon a wide range of attitudes that include affective responses.

Of course, framing the affective puzzle merely in terms of the difficulties appreciators find when asked to respond in ways they consider ethically inappropriate does not seem puzzling at all: appreciators resist the invitation to respond precisely because of the deviant nature of the prescribed responses. ${ }^{7}$ However, it is important to note that we find variations in our affective responses to immorality in fictional scenarios. What results puzzling is that we fail to adopt the prescribed deviant affective responses in some cases but not in others. Various authors have noted that appreciators do not always resist responding in ways they would normally consider inappropriate. Shaun Nichols refers to the phenomenon of discrepant affect, in which "Sometimes our affective responses to imaginings differ in important ways from our responses to belief" (Nichols 2006, 464). Matthew Kieran talks about emotional asymmetries that are manifested in how "In engaging with works of fiction we often allow ourselves to have emotions to the same kind of events that stand in contrast to the type of emotions we would ordinarily have" (Kieran 2010, 683). This phenomenon of affective variation is puzzling because we seem to treat similar fictional scenarios (i.e. fictional scenarios that involve moral deviance) differently, and it is not clear why we do so: appreciators respond with what they recognise as deviant affective responses to some fictional scenarios but not others. The affective puzzle therefore refers to why we find variations in how we respond to moral deviance in different fictional scenarios.

The phenomenon of affective resistance is relevant for understanding the differences in our engagement with rough heroes and heroines precisely because we can find an asymmetry in appreciators' responses to narratives that clearly present male and female protagonists as immoral. If rough protagonists cause resistance due to the narrative's invitation to ally with deeply immoral characters, why do appreciators manage to overcome resistance and display sustained, strong pro-attitudes toward rough heroes?

Recent literature on resistance-related puzzles has noted the importance of narrative context in explaining why some fictional scenarios trigger resistance and others do not. Some authors, like Bence Nanay (2010), Jonathan Weinberg (2008) and Shen-yi Liao (2016), have turned to genre to explain variability within resistance phenomena. For example, Liao argues that resistance phenomena emerge when a fictional prescription violates genre conventions: appreciators experience difficulties because what can and can't be true in a story depends on 
genre conventions, and because appreciators' narrative engagement and responses depend on expectations that stem from genre conventions as well. Other authors have turned to narratives' aesthetic resources to explain variability in our engagement with immorality in fiction. For example, Kieran (2010) argues that narrative artistry is responsible for the asymmetry in cognitive-affective attitudes toward certain fictional scenarios.

In the case of rough heroes, narrative context can explain the affective puzzle away in that it can explain why appreciators overcome their initial resistance to ally with deeply morally flawed protagonists. Rough heroes might be immoral, but narratives' aesthetic features emphasise other character traits, such as intelligence, strength, charm, that are framed as highly attractive. Eaton argues that overcoming resistance is possible thanks to a widespread "contamination tendency", in which our assessments are "often unconsciously contaminated by the influence of positive responses to unrelated attributes." (Eaton 2013, 377) Narrative context allows narratives to emphasize the immoral character of the hero for appreciators to condemn him, but at the same time it allows the narrative to generate pro-attitudes strong enough to ground non-moral allegiance. ${ }^{8}$ In this sense, while the narrative doesn't make it true in the fictional world that the hero's moral failings are moral virtues, it does make the proattitudes narratively appropriate: narrative context makes appreciators' allegiance the fitting attitude. While allegiance is generally grounded on moral judgement, narratives that feature rough heroes prescribe a type of allegiance that is not grounded on moral approval, but on emotional engagement. In these cases, allegiance depends on a narrative's ability to exploit the influence of non-moral judgements on moral appraisals (Plantinga 2010; Eaton 2013). Appreciators experience strong affective responses to the hero that lead them to bracket their moral appraisals, and impact their overall pro-attitudes.

\section{Resisting rough heroines}

Accounts that note the relevance of narrative context in our engagement with moral deviance in fiction seem attractive because they can solve the affective puzzle and account for variability within resistance phenomena: some instances of moral deviance do not prompt resistance, while others do, because of certain features of the narratives in which we find these deviant scenarios. However, focusing on narrative context still fails to explain resistance to rough heroines: it can be argued that narratives that feature rough heroines present the same features that ground non-moral allegiance to rough heroes, and yet they either fail or find it more 
difficult to ground allegiance to morally flawed female protagonists. What I want to argue in what follows is that explaining the puzzle of rough heroines requires going beyond narrative context: I believe resistance to morally transgressive female characters can be explained by attending to the violation of gender norms and the challenge to power dynamics.

As I said in the introduction, the puzzle of rough heroines refers to the asymmetry we find in our engagement with male and female characters who transgress moral norms: we seem to ally with rough heroes relatively easily, but we resist allying with rough heroines. ${ }^{9}$ It is interesting to note that we can find many instances of antiheroines. But if we examine them closely we can see that they often exploit gender norms and expectations in one way or another to secure narrative engagement. We have antiheroines with a strong motherly instinct, such as Beatrix Kiddo in Kill Bill or Geum-ja Lee in Lady Vengeance. We can find femmes fatales, like Marvel's Black Widow or Nikita. More significantly perhaps, we can find several instances of antiheroines who are survivors of sexual violence, like Lizbeth Salander or Jessica Jones. That is, it would seem that audiences display pro-attitudes toward flawed female characters inasmuch as they are carers, objects of the male gaze, or victims.

The few instances of morally flawed female protagonists often fail to achieve rough heroine status. As I said before, we can think of the difference between antiheroes/antiheroines and rough heroes/heroines as a matter of degree: the degree of severity of their immoral actions, their degree of remorse, and the degree of moral relevance of their redeeming features. Setting a few exceptions aside, morally flawed female characters mostly fail to comply with the features identified in Section One. The moral flaws of female protagonists are often not as severe. For example, as Margrethe Bruun Vaage notes, the few morally flawed female protagonists in popular TV are not allowed to be as transgressive as their male counterparts: their transgressions are not as grievous, their family life is not affected by their misdeeds, and their moral flaws are presented in a comedic and endearing tone (Vaage 2016, 171-180). Morally flawed female characters are often presented as engaging in immoral actions mainly as means to achieve other (moral) aims; for example, survivors of violence are portrayed as looking for justice. The redeeming features of morally flawed female characters are often morally relevant: for example, their desire for justice, or their devotion to their children.

We can find very few instances of morally flawed female characters that fit the characteristics of rough protagonists; for example, Gone Girl's Amy Dunne, House of Cards' Claire Underwood, Natural Born Killers' Mallory Knox. These are characters whose flaws are 
grievous and an integral part of both their personality and the narratives that feature them; these women intentionally engage in immoral actions and their remorse is not a central part of the narrative; appreciators are not prescribed to forgive them or dismiss their actions as a result of misfortune, weakness or ignorance; and their vices are not outweighed by other morally relevant features. Nevertheless, identifying these characters as rough heroines is not without challenge. As I said at the beginning, Fincher's film adaptation of Gone Girl positions Amy as an antagonist, and thus does not seem to endorse her by prescribing allegiance. House of Cards, on the other hand, presents in seasons one to four an interesting contrast between the moral transgressions that make Claire and Frank Underwood rough protagonists: she is a ruthless, selfish, and drunk with power woman who is uninterested in motherhood; he is a ruthless, selfish, drunk with power man who has murdered several people. Finally, Mallory Knox begins her life of crime by murdering her sexually abusive father and enabling mother after being saved by Mickey. So, it might still be problematic to identify them as clear instances of rough heroines: Amy is not clearly endorsed by the film's perspective, Claire is not as morally transgressive as her male counterpart, and Mallory has motivations that could potentially be morally relevant.

It might be tempting to argue that on closer inspection we cannot actually find many clear instances of rough heroes either. That is, if we raise the bar so high for rough heroines in terms of the gravity of their misdeeds, we should do the same for rough heroes; it might turn out that most instances of morally flawed male characters also fail to achieve rough hero status. If the asymmetry in our engagement with male and female characters who transgress moral norms refers to a gender imbalance in numbers, it would be essential to show that we find many more examples of rough heroes than rough heroines.

However, establishing a clear and categorical distinction between rough heroes/heroines and antiheroes/antiheroines is not necessary to bring out the asymmetry in our engagement with male and female characters who transgress moral norms. What is important to point out is that the gender imbalance at the heart of the puzzle refers not simply to finding very few instances of rough heroines, but to the type and severity of moral flaws female characters get away with to sustain imaginative engagement. Or rather, that the gender imbalance in terms of numbers of rough heroes and heroines is due to the gender imbalance in the type and severity of moral flaws. That is, even if we were to argue that rough protagonists in general are rare, and that most morally flawed male and female characters are antiheroes/antiheroines, we can certainly find an asymmetry in the type and severity of moral transgressions allowed for male and female 
characters. Think, for example, of the contrast between two drug dealers in popular TV: Weeds' Nancy Botwin and Breaking Bad's Walter White. Nancy's moral transgressions involve selling marihuana and implicating her children in her illegal business. Walter's moral transgressions include not only selling methamphetamine and implicating his family, but killing several people, poisoning a child to further his interests, and being abusive toward his wife.

As I said before, I believe we can explain resistance to rough heroines by attending to the violation of gender norms. Gender norms are those that "enable one to excel in the social position constituting the class women" (Haslanger 2000, 53, note 9). These include norms of appearance, bodily comportment, and behaviour. Gender norms include sanctions and expectations that position individuals classified as women in a specific social relation; in particular, gender norms position individuals identified as women in a power relation in which men are dominant and women are subordinate. What I want to argue is that we resist allying with rough heroines because in being morally transgressive, they break with gender norms and expectations. It can be said that men being morally transgressive somehow fits in with gender norms. Think about "boys will be boys". We expect and socialise boys to be adventurous and dissenting, and we regard these features as valuable and endearing: boys are mavericks. But with the expectation of boys and men breaking the rules comes the expectation that things might go wrong sometimes. Moral transgressions might not be actively encouraged, but they seem to be a (hopefully unwanted) consequence of men's transgressive character.

In the case of women, moral transgressions imply breaking with what we value in women. The radical transgressions that characterise rough heroines imply that they need to part with those features that have traditionally been regarded (and valued) as being womanly: tenderness, graciousness, selflessness, vulnerability, sensuality. Women are brought up to be likeable and accommodating, and rough heroines aspire to just the opposite. Moreover, it could be that we often resist rough heroines because to endorse their moral transgressions would imply a challenge to power dynamics. While rough heroes are endearing because they take the direction of their lives into their own hands, rough heroines might be resisted precisely because they challenge women's subordinate position. In challenging women's role as passive, vulnerable and docile beings, rough heroines bring forward the social structures that keep women oppressed. Why wouldn't appreciators feel uncomfortable?

Finally, it's worth noting how the puzzle of rough heroines throws light onto how gender expectations and norms impact the construction of and engagement with flawed female 
characters in fiction when compared with two other different cases: villainesses and "nasty" heroines. Villainesses are morally flawed characters that do not demand appreciators allegiance, they are antagonists. Contrary to rough heroines, villainesses seem to be as commonly found in narratives as villains; one need not look further than children's literature, where witches, cruel stepmothers, and evil queens are a common trope. The reason why we might not find an asymmetry between male and female antagonists is that villainesses conform to certain negative gender expectations: they are manipulative, cunning, astute, frivolous, vengeful, etc. Indeed, these features could even be said to be stereotypically female negative qualities. So, what is the difference between villainesses and rough heroines, and why aren't these negative features enough to ground rough heroines? The key difference is that while both might be morally flawed female characters, rough heroines are meant to elicit strong proattitudes that can ground appreciators' allegiance. It's not unthinkable that women might possess negative character traits. But while negative qualities such as being manipulative, cunning, or vengeful, might be thought of as stereotypically female, these features are still gender norm discordant: gender norms are about what we value in individuals gendered as women; as characterised by Haslanger, gender norms refer to features that enable individuals to excel as women. So, while we might think that it is common for women to be sly, sly women are bad women. And while bad women might make easy antagonists, they find it harder to secure allegiance.

"Nasty" heroines, on the other hand, are another example of "unlikeable" female protagonists. What characterises "nasty" heroines is that they are protagonists whose flaws are simply gender norm violations. "Nasty" heroines are "flawed" or "unlikeable" simply because they are not womanly. "Nasty" heroines are career driven women who are ambitious and who don't value motherhood (like Homeland's Carrie Mathison), messy or dysfunctional women (like Young Adult's Mavis Gary), overtly sexual women (like Sex and the City's Samantha Jones), etc. "Nasty" heroines can often be mistaken for rough heroines, but there is a key difference between them: contrary to rough heroines, whose flaws are primarily moral, the transgressions that make "nasty" heroines "unlikeable" are not primarily moral. The difference between rough and "nasty" heroines could be put as follows: rough heroines are resisted because in being immoral, they are not being womanly; "nasty" heroines, on the other hand, are seen as "flawed" because in not being womanly, they are taken to be morally flawed. What the common confusion between these two different types of flawed female characters reveals is that we 
seem to take violations of gender norms to be so serious that we come to regard them as moral flaws.

\section{Appreciators' interpretive horizons}

What does the puzzle of rough heroines say about narrative engagement? Of course the causes of resistance to rough heroines need to be examined in more depth. But what I want to note is that rough heroines reveal that variability within resistance phenomena cannot be explained only by attending to narrative context. On the contrary, resistance to rough heroines suggests that narrative engagement is also partly constrained by appreciators' socio-historical context. As such, rough heroines reveal that resistance phenomena are grounded on another feature of narrative engagement that has been largely overlooked: appreciators' interpretive horizons.

Appreciators don't approach fictional narratives as empty vessels. Narrative engagement is historical in that appreciators are socio-historically situated. According to Hans-Georg Gadamer, a horizon refers to "the range of vision that includes everything that can be seen from a particular vantage point" (Gadamer 2004, 301). Appreciators' socio-historical situatedness thus determines their interpretive horizons. While I don't want to say anything about the ontological significance of such situatedness, I do want to say that narrative engagement inevitably involves an interpretive process that is partly determined by our socio-historical situation. An interpretive process is necessarily involved in understanding the relation between explicit and implicit fictional prescriptions, in identifying the manifested attitude of the work, in determining what the appropriate responses to the fictional perspective might be, etc. Further, this interpretive process is partly determined by our socio-historical situatedness, by our horizon.

So what are interpretive horizons? I take interpretive horizons to involve a range of conscious and unconscious attitudes that are partly affected by our socio-historical context, and that impact how we understand and relate to others. For example, Linda Martín Alcoff (2006, 94102) notes how these horizons impact gender and racial identity: interpretive horizons are involved in how we construct gender and race, and so they include conscious and unconscious assumptions and biases. In short, interpretive horizons partly determine how we are gendered and racialized, how we are seen, how we are treated. 
Because narrative engagement involves an interpretive process, interpretive horizons partly determine how we understand and respond to works of fiction. They dictate our orientation towards works: they focus our attention to certain aspects of the work over others, they partly determine what we care about in fiction. Moreover, interpretive horizons impact how we relate to others in fictional worlds as well. In the case of rough heroines, interpretive horizons impact our willingness to ally with morally flawed female characters due to how we understand gender identity. Gender norms and expectations bring with them additional obstacles in our imaginative engagement with morally flawed female characters in fiction. And this means narratives featuring rough heroines face additional challenges in prescribing allegiance to female characters that subvert gender norms.

By determining how we engage with morally flawed female characters in fiction, interpretive horizons impact narratives' aesthetic value. As I said at the beginning, Eaton argues that rough heroes represent a special kind of aesthetic achievement in that they make appreciators overcome their initial resistance to respond with the pro-attitudes necessary to ground allegiance. In order to move us and get us to respond in ways we wouldn't ordinarily respond, works that feature rough heroes require a great command of other formal features, such as character development, narrative structure, intensity, and expressive power. Because gender norms and expectations represent additional obstacles in imaginatively engaging with morally flawed female characters, rough heroines bring with them additional creative challenges. Works featuring rough heroines need to deploy successfully different strategies or do more work in commanding the formal features that can ground strong and sustained pro-attitudes to morally flawed protagonists.

Nevertheless, it is important to emphasize that it is not the subversion of gender norms itself that constitutes an aesthetic achievement. Rather, given certain contextual considerations, the subversion of gender norms requires a more successful command of other formal features to ground strong and sustained pro-attitudes to prescribe allegiance; and it is this allegiance in the face of additional challenges that constitutes a special kind of aesthetic achievement. Narratives featuring rough heroines are not aesthetically valuable because (or when) they subvert gender norms. They are aesthetically valuable because (or when) they successfully prescribe allegiance; the subversion of gender norms makes allegiance more difficult to achieve, and thus a greater aesthetic achievement. This means that interpretive horizons impact the aesthetic value of works only insofar as they impact which features of works we consider aesthetically significant, or the degree of aesthetic significance of certain features. 
If the subversion of gender norms and expectations is not an aesthetic achievement in itself, could we say that works featuring rough heroines represent a political or moral achievement? Taking interpretive horizons into account it is possible to say that given certain contextual considerations, certain features of works become morally or politically salient. That is, given the prevalence of gender norms, it might be politically or morally significant that works manage to make appreciators engage with female characters that subvert gender norms. But whether this constitutes a political achievement depends on what Susan Feagin (1995) calls works' de facto significance: on the impact such a work could have on broader cultural configurations, and on the impact it could have in reconfiguring our interpretive horizons. While a single work might not actually subvert damaging gender norms, a work's power to get audiences to engage with gender discordant female characters could be politically and morally significant in virtue of its power to affect emerging cultural patterns. Interpretive horizons thus allow us to provide a more complex criticism of the creation and appreciation of works.

\section{Concluding remarks}

In this paper, I have tried to show that the puzzle of rough heroines reveals that resistance phenomena are context dependent not only in that narrative context impacts how we engage with moral deviance in fiction, but in that the socio-historical context of appreciators conditions their narrative engagement in important ways. Although the most recent literature on imaginative resistance has emphasised context, authors have focused on the context of propositions in works of fiction. But a satisfactory account of resistance phenomena and narrative engagement must also take into consideration the contexts in which these propositions are received.

I have argued that, although the causes of resistance to female characters who transgress moral norms need to be examined in more depth, rough heroines reveal that resistance phenomena are also grounded on appreciators' interpretive horizons. These horizons depend on the sociohistorical context of reception of the narrative. While authors, like Liao and Kieran, are right to note that narrative context plays a very important role in how we engage with immorality in fiction, I believe appreciators' interpretive horizons to be as important in explaining how receptive audiences are to moral deviance in fictional scenarios. Interpretive horizons seem to be particularly relevant in explaining why we fall for rough heroes but resist rough heroines. But also taking interpretive horizons into consideration, I would like to end with a prediction: 
as gender norms and expectations continue to be challenged, we might finally be on the verge of embracing rough heroines.

\section{References}

Alcoff, Linda Martín. 2006. Visible Identities: Race, Gender, and the Self. Oxford; New York: Oxford University Press.

Burkeman, Oliver. 2013. "Gillian Flynn on Her Bestseller Gone Girl and Accusations of Misogyny." The Guardian. https://www.theguardian.com/books/2013/may/01/gillianflynn-bestseller-gone-girl-misogyny.

Carroll, Noël. 2008. The Philosophy of Motion Pictures. Oxford: Blackwell.

_. 2013. "Rough Heroes: A Response to A. W. Eaton." The Journal of Aesthetics and Art Criticism 71 (4): 371-75.

Coen, Jessica. 2014. “Gone Girl’s Biggest Villain Is Marriage Itself.” Jezebel. http://jezebel.com/gone-girl-s-biggest-villain-is-marriage-itself-1642978659.

De Sousa, Ronald. 2010. “The Mind's Bermuda Triangle: Philosophy of Emotions and Empirical Science.” In The Oxford Handbook of Philosophy of Emotion, edited by Peter Goldie, 95-117. New York: Oxford University Press.

Dobbins, Amanda. 2014. "Yes, Gone Girl Has a Woman Problem.” Vulture. http://www.vulture.com/2014/10/yes-gone-girl-has-a-woman-problem.html.

Dockterman, Eliana. 2014. "Is Gone Girl Feminist or Misogynist?” Time. http://time.com/3472314/gone-girl-movie-book-feminist-misogynist/.

Eaton, A. W. 2010. "Rough Heroes of the New Hollywood.” Revue Internationale de Philosophie 4 (254): 511-24.

—. 2012. "Robust Immoralism." The Journal of Aesthetics and Art Criticism 70 (3): 281-92.

—. 2013. "Reply to Carroll: The Artistic Value of a Particular Kinds of Moral Flaw." The Journal of Aesthetics and Art Criticism 71 (4): 376-80.

Feagin, Susan L. 1995. "Feminist Art History and De Facto Significance.” In Feminism and 
Tradition in Aesthetics, edited by Peggy Zeglin Brand and Carolyn Korsmeyer, 305-25. University Park, PE: The Pennsylvania State University Press.

Gadamer, Hans-Georg. 2004. Truth and Method. Edited by Joel Weinsheimer and Donald G. Marshall. Second edi. London; New York: Continuum.

Gendler, Tamar Szabó. 2000. “The Puzzle of Imaginative Resistance.” The Journal of Philosophy 97 (2): 55-81.

- 2006. "Imaginative Resistance Revisited." In The Architecture of the Imagination: New Essays on Pretence, Possibility, and Fiction, edited by Shaun Nichols. Oxford: Oxford University Press.

Goldie, Peter. 2003. "Narrative, Emotion, and Perspective." In Imagination, Philosophy and the Arts, edited by Matthew Kieran and Dominc M. Lopes, 55-69. London: Routledge.

Haglund, David. 2014. “The Strange Thing David Fincher Does With the 'Cool Girl' Speech in Gone Girl." Slate. http://www.slate.com/blogs/browbeat/2014/09/29/gone_girl_movie_cool_girl_speech_is _in_it_but_there_are_no_men_seen_during.html.

Haslanger, Sally. 2000. "Gender and Race: (What) Are They? (What) Do We Want Them To Be?" Noûs 34 (1): 31-55.

Hume, David. 1985. “On the Standard of Taste.” In Essays: Moral, Political and Legal, 227 49. Indianapolis: Liberty Fund.

John, Eileen. 2006. “Artistic Value and Opportunistic Moralism.” In Contemporary Debates in Aesthetics and the Philosophy of Art, edited by Matthew Kieran, 331-41. Oxford: Blackwell.

Kieran, Matthew. 2010. "Emotions, Art, and Immorality." In The Oxford Handbook of Philosophy of Emotion, edited by Peter Goldie, 681-703. Oxford: Oxford University Press.

Lang, Nico. 2014. 'David Fincher's Gone Girl Betrays the Crucial Balance of Gillian Flynn's Novel." The A.V. Club. http://www.avclub.com/article/david-finchers-gone-girl-betrayscrucial-balance-g-209988.

Liao, Shen-yi. 2016. “Imaginative Resistance, Narrative Engagement, Genre.” Res 
Philosophica 93 (2): 461-82.

Liao, Shen-yi, and Tamar Szabó Gendler. 2016. “The Problem of Imaginative Resistance.” In The Routledge Companion to Philosophy of Literature, edited by Noël Carroll and John Gibson, 405-18. New York; London: Routledge.

McGregor, Rafe. 2014. “A Critique of the Value Interaction Debate.” The British Journal of Aesthetics 54 (4). Oxford University Press: 449-66.

Moran, Richard. 1994. "The Expression of Feeling in Imagination.” The Philosophical Review 103 (1): 75-106.

Nanay, Bence. 2010. "Imaginative Resistance and Conversational Implicature.” The Philosophical Quarterly 60: 586-600.

Nichols, Shaun. 2006. “Just the Imagination: Why Imagining Doesn't Behave like Believing." Mind and Language 21 (4): 459-74.

Plantinga, Carl. 2010. “'I Followed the Rules, and They All Loved You More': Moral Judgment and Attitudes toward Fictional Characters in Film.” Midwest Studies In Philosophy 34 (1): 34-51.

Smith, Murray. 1995. Engaging Characters: Fiction, Emotion, and the Cinema. Oxford: Oxford University Press.

— 1999. “Gangsters, Cannibals, Aesthetes, or Apparently Perverse Allegiances.” In Passionate Views: Film, Cognition, and Emotion, edited by Carl Plantinga and Greg M. Smith, 217-38. Baltimore, MD: Johns Hopkins University Press.

— 2011. "Just What Is It That Makes Tony Soprano Such and Appealing, Attractive Murderer?" In Ethics at the Cinema, edited by Ward E. Jones and Samantha Vice, 6690. Oxford: Oxford University Press.

Todd, Cain Samuel. 2009. "Imaginability, Morality, and Fictional Truth: Dissolving the Puzzle of 'Imaginative Resistance."” Philosophical Studies: An International Journal for Philosophy in the Analytic Tradition 143 (2): 187-211.

Tullmann, Katherine. 2016. "Sympathy and Fascination.” British Journal of Aesthetics 56 (2): 115-29.

Vaage, Margrethe Bruun. 2016. The Antihero in American Television. New York: Routledge. 
Walton, Kendall. 2006. “On the (So-Called) Puzzle of Imaginative Resistance.” In The

Architecture of the Imagination: New Essays on Pretence, Possibility, and Fiction, edited by Shaun Nichols. Oxford: Oxford University Press.

Weatherson, Brian. 2004. "Morality, Fiction, and Possibility.” Philosophers' Imprint 4 (3): $1-27$.

Weinberg, Jonathan M. 2008. "Configuring the Cognitive Imagination.” In New Waves in

Aesthetics, edited by Kathleen Stock and Katherine Thomson-jones, 203-23.

Basingstoke: Palgrave Macmillan.

Yablo, Stephen. 2002. "Coulda, Woulda, Shoulda." In Conceivability and Possibility, edited by Tamar Szabó Gendler and John Hawthorne, 441-92. Oxford: Oxford University

Press.

\footnotetext{
${ }^{1}$ In an interview for The Guardian, Gillian Flynn notes the importance of meaningfully engaging with the motivations of morally flawed female characters in order to avoid the 'psycho bitch' trope: "I don't write psycho bitches. The psycho bitch is just crazy - she has no motive, and so she's a dismissible person because of her psycho-bitchiness" (Burkeman 2013). In the book, allying with Amy depends on the exposition of her motives mainly through the Cool Girl monologue. For criticisms of Fincher's insufficient engagement with Amy's complex motives see: (Coen 2014; Haglund 2014; Dockterman 2014; Dobbins 2014; Lang 2014).

${ }^{2}$ According to Murray Smith allegiance depends on the moral evaluation of characters by appreciators: "To become allied with a character, the spectator must evaluate the character as representing a morally desirable (or at least preferable) set of traits, in relation to other characters within the fiction" (Smith 1995, 188). To explain allegiance to immoral characters, Smith argues that the moral traits that ground allegiance do not need to be evaluated by audiences in absolute terms. In some cases, audiences ally with a protagonist who has morally undesirable traits because these are contrasted with villains' more undesirable traits (Smith 1999). Further, allegiance to depraved characters is grounded on two facts: on their normalcy (audiences are groomed to see that immoral characters are just like them), and on the alluring character of their misdeeds. (Smith 2011)

${ }^{3}$ It might be problematic to argue that narratives necessarily prescribe allegiance toward rough heroes. For example, Eileen John (2006) and Rafe McGregor (2014) have noted that talking about prescribed responses risks oversimplifying how appreciators engage with works: particular responses to works might vary without this meaning we have failed to understand or appreciate the work. For this reason, I argue that the notion of allegiance, rather than sympathy, is necessary to understand engagement with rough heroes. While particular responses might vary, it is important to say that appreciators will have failed to appropriately grasp the narrative if they have failed to ally with the rough hero. Allegiance toward immoral characters doesn't require appreciators to sympathise with the hero throughout the entire narrative. Allegiance mandates appreciators to remain invested in seeing the rough hero prevail; what this 'prevail' entails depends on the context of each narrative, but it does involve remaining invested in seeing rough heroes persist and take their vices to the last consequences. To this end, allegiance should be cashed out in terms of strong pro-attitudes that are sustained throughout the narrative. But the particular proattitudes encompassed by allegiance might vary from narrative to narrative, from appreciator to appreciator, and even vary in particular moments within a narrative. Allegiance might be sustained on pity, admiration, or even fascination. Further work will need to go into what sort of pro-attitudes are strong enough to ground non-moral allegiance (for example, see Katherine Tullman's "Sympathy and Fascination" (2016)).

${ }^{4}$ This paper focuses on resistance to moral deviance exclusively because the transgressions appreciators are meant to endorse when allying with rough heroes are moral transgressions. There is a widespread disagreement regarding the nature of the deviant scenarios that prompt problems in imaginative engagement. Gendler $(2000,2006)$, for
} 
example, argues that moral deviance is central to resistance puzzles. Some authors, like Yablo (2002) and Todd (2009), claim it has something to do with the application of certain concepts. Others, like Walton (2006) and Brian Weatherson (2004) have noted that imaginative resistance arises when appreciators are faced with deviant evaluative scenarios in general. Most authors, nevertheless, accept that other non-evaluative fictional scenarios can also cause problems of imaginative barriers, as it is the case for scenarios that conflict with simple necessary truths. For an overview of imaginative resistance see (Liao and Gendler 2016).

5 As I will argue in the following paragraphs, I don't think all resistance-related puzzles centrally involve imaginative difficulties. For this reason, I follow Liao's (2016) suggestion to drop the term "imaginative resistance" and opt instead to refer to "resistance phenomena" or "resistance-related puzzles".

${ }^{6}$ This fifth resistance-related puzzle might be exclusive to the kind of exercise of imagination involved in narrative engagement. Narrative engagement involves what Moran (1994) calls "vividness". That is, the type of imaginative project that could trigger affective resistance is one that "has less to do with imagining something to be the case" and more to do with "the ability to make connections between various things, to notice and respond to the network of associations that make up the mood or emotional tone of a work" (Moran 1994, 86).

${ }^{7}$ One might further object to the recognition of the affective puzzle that failing to display the affective attitudes prescribed toward deviant scenarios is not puzzling at all: appreciators simply fail to respond in the ways prescribed because the prescribed responses don't fit the fictional scenario. However, in the case of fictional narratives, works make use of various aesthetic resources to present the prescribed responses as fitting. For this reason, it is relevant to keep in mind the distinction between ethical and narrative appropriateness proposed by Goldie. Narrative appropriateness refers to whether prescribed responses are fitting according to the relevant aesthetic considerations; ethical appropriateness refers to the appropriateness of responses according to moral and prudential considerations (Goldie 2003, 61-64). In some cases, as it is the case for narratives that feature rough heroes, appreciators' responses to deviant scenarios in fiction simply follow what is narratively appropriate, given the relevant aesthetic considerations. In some other cases, appreciators do not seem to respond in the ways prescribed because ethical appropriateness trumps other aesthetic considerations. Thus, the affective puzzle refers to why in some cases we adopt the affective attitudes prescribed by certain fictional scenarios that involve deviance, but not in others.

${ }^{8}$ Smith disagrees with the notion of non-moral allegiance. He argues that even in these cases, the non-moral elements do not displace moral factors, but rather help in ignoring some morally relevant features in favour of other morally relevant features (Smith 2011, 84).

${ }^{9}$ It is possible to interpret the asymmetry in two different ways. According to a strong version of the asymmetry, resistance entails that female characters are not allowed to be as morally transgressive as their male counterparts; as a result, morally flawed female characters often fail to achieve rough heroine status. According to a weak version of the asymmetry, resistance entails that the moral transgressions allowed for female characters are of $a$ different kind than those allowed for male characters; in this case, rough heroines are not simply the female counterparts of rough heroes but present different character traits. I opt for a strong reading of the asymmetry, but I believe my argument applies for the weak version as well: in this case, gender norms would impact the type of moral transgressions that make a female character a rough heroine, instead of gender norms having an impact on the severity of the moral transgressions, as claimed by the strong version of the asymmetry. 